\title{
El turismo en la provincia mexicana. Notas de prensa 1886-1945
}

\author{
Eugenio Mercado López* \\ Universidad Michoacana de San Nicolás de Hidalgo (México)
}

\begin{abstract}
Resumen: El turismo en México tuvo una primera época de auge en la década de 1930, como resultado de la difusión de esa actividad en Iberoamérica desde fines del siglo XIX y el impulso que le dieron a esa actividad los gobiernos surgidos de la Revolución Mexicana. No obstante su importancia, los efectos de las políticas nacionales en torno al turismo en el ámbito regional y local del país durante esa temporalidad han sido abordados de forma limitada. Por lo anterior, a partir de notas de prensa, en el presente texto se identifican los procesos de difusión del turismo y sus efectos en algunos de los estados y ciudades de la provincia mexicana durante la temporalidad de estudio; con ello se pretende motivar la realización de nuevas investigaciones que permitan construir una visión más completa acerca del desarrollo de esta actividad, sus efectos y permanencias en las diversas regiones de México.
\end{abstract}

Palabras Clave: Prensa; Turismo; Patrimonio; México.

Tourism in the mexican provinces. notes from the press, 1886-1945

Abstract: Tourism in Mexico had a first boom period in the 1930s, as a result of the spread of the activity in Hispanic America from the end of the 19th century onwards and spurred by the successive Mexican Revolution Governments' policies. Despite its importance of the subject, the effects of the national policies on the tourism at the regional and local levels of the country at that time have been the object of limited research. Therefore, based on press releases, the present text identifies the processes of promotion of tourism and its effects in some of the states and cities In the Mexican provinces during the study period in the hope hat this will motivate further research that allows us to build a more complete vision of how the activity evolved, its effects and the lasting legacy in the different regions of Mexico.

Keywords: Press; Tourism; Heritage; Mexico.

\section{Introducción}

A través del presente texto se busca identificar los procesos de difusión del turismo y sus efectos en algunos de los estados y ciudades de la provincia mexicana desde finales del siglo XIX hasta las primeras décadas del siglo XX. Este trabajo forma parte de una investigación más amplia y parcialmente publicada (Mercado 2016 y 2018), en la cual se plantea la importancia de identificar y valorar la conjunción del patrimonio cultural y natural con el turismo en México, desde su origen hasta su incorporación en los planes y programas de los gobiernos posrevolucionarios durante las primeras décadas del siglo XX.

El estudio de la relación entre patrimonio y turismo bajo una visión retrospectiva de largo plazo parte del supuesto de que en la actuación pública contemporánea subyacen conceptualizaciones y prácticas que se remontan al origen y evolución de la intervención del Estado en esa actividad. Por tanto, ese conocimiento es susceptible de incorporarse en la formulación y aplicación de las actuales políticas culturales y turísticas en sitios con un rico legado cultural y natural. Esto es particularmente importante para México si se considera que los problemas, objetivos y estrategias planteadas en los planes

Universidad Michoacana de San Nicolás de Hidalgo (México); E-mail: eugenio_mercado@hotmail.com; https://orcid. org/0000-0003-0352-413 
y programas de los gobiernos posrevolucionarios son, en buena medida, similares a los considerados en las políticas contemporáneas.

En la actualidad, México enfrenta el reto de superar la pobreza rural y urbana, lograr un mayor crecimiento y mejorar las condiciones de vida de sus habitantes. El Plan Nacional de Desarrollo 2019-2024, recientemente publicado, propone "[...] la creación de empleos dignos, el desarrollo regional, la edificación de un estado de bienestar y el impulso a los procesos de construcción de la paz [...]" para ello se espera que "[...] los programas sociales sectoriales tengan una incidencia concreta en la mejoría de las condiciones de vida en las principales zonas expulsoras de mano de obra [...]"; lo cual se pretende lograr a partir de proyectos regionales como es el caso del Tren Maya (PND 2019-2014, 2019: 31). Es importante observar que las regiones con mayor incidencia de pobreza en México (CONEVAL, 30 de agosto de 2017) son las áreas con una mayor concentración de bienes culturales y naturales en el país (Geoportal INAH, 2017), lo cual es una oportunidad para que el turismo contribuya eficientemente en los objetivos nacionales.

Pese a la validez de los objetivos planteados, en los recientes programas de turismo cultural en México se observa que en varios de los sitios de tradición intervenidos y dispuestos para el turismo, lejos de contener expresiones de cultura producto de la natural evolución de las comunidades son, en muchos casos, una re-presentación en función de la expectativa del visitante y de la visión de quienes planifican y gestionan esa actividad (Alvarado y López, 2018). Por lo anterior, si la competitividad turística de un sitio depende de la posibilidad de generar un perfil atractivo y de crear una imagen que le proteja de las tendencias homogeneizadoras de la globalización (Rodríguez, 1998: 63), la revisión del proceso histórico que ha configurado esa actividad y los atractivos en los cuales se sustenta es de importancia, porque ese conocimiento permite identificar los valores y rasgos distintivos que lo diferencian de otros lugares, atributos que pueden salvaguardarse y transmitirse para el sostenimiento del sistema turístico.

Para la identificación del proceso de difusión y del impacto del turismo en el territorio mexicano se acudió a la búsqueda aleatoria de notas de prensa, logrando localizar 366 artículos relacionados con el turismo en periódicos privados y oficiales del interior del país publicados entre 1886 y 1945, realizando un análisis de contenido y de discurso de los textos. Es importante señalar que, al no ser producto de una búsqueda exhaustiva, los resultados obtenidos no pretenden ser concluyentes sino motivar la realización de nuevos y más amplios estudios en el ámbito local que permita conocer la experiencia histórica en el tema.

La clasificación y sistematización de las notas de prensa permitió generar algunos datos. En cuanto a los sitios mencionados, el $15.5 \%$ hacía referencias a noticias relativas al ámbito nacional, en tanto que el 3.86\% fueron hechos acaecidos en la Ciudad de México. La mención por estado de la república se distribuye de la siguiente forma: Jalisco (48.21\%), Colima (7.71\%), Morelos (4.68\%), Sinaloa (3.58\%), Nuevo León (3.03\%), Michoacán (2.20\%), Coahuila (1.38\%), Tamaulipas (1.38\%), Guerrero (1.10\%), Oaxaca (1.10\%), Yucatán (1.10\%)., Baja California (0.83\%), Puebla (0.83\%), Estado de México (0.55\%), Guanajuato (0.55\%), Nayarit (0.55\%), Veracruz (0.55\%), Campeche (0.28\%), Chiapas (0.28\%), Chihuahua $(0.28 \%)$, Hidalgo $(0.28 \%)$, Querétaro $(0.28 \%)$ y San Luis Potosí $(0.28 \%)$. La frecuencia en la mención de los estados del país es proporcional a la procedencia de los diarios consultados, ya que el $79.78 \%$ corresponde a un periódico publicado en Guadalajara, capital del estado de Jalisco; no obstante el sesgo que esto pude significar, también permite identificar particularmente el impacto del turismo en la región centro occidente del país durante el período de estudio.

La agrupación de las notas por contenidos afines permitió identificar las siguientes temáticas: Asociaciones y Comités de Turismo (33\%), Atractivos turísticos, Excursiones (15\%), Estadísticas (9\%), Legislación (7\%) Comunicaciones y transportes (5\%), Publicidad (4\%), Dependencias públicas (4\%), Imagen urbana (2\%) y Guías de turistas (2\%). El $11.75 \%$ de las notas fueron publicadas entre 1886 y 1928, el 84.4\% entre 1929 y 1941, en tanto que el restante $3.83 \%$ aparecieron entre 1942 y 1945 .

Para la presentación de resultados, los contenidos de las notas se han agrupado por su recurrencia en temas afines como son: la acción del gobierno, asociaciones y comités de turismo, la creación de una imagen urbana para el turismo, los servicios de hospedaje y guías de turistas, la propaganda de viajes y excursiones, así como las estadísticas del turismo, temas que se desarrollan a continuación.

\section{La acción del gobierno}

Con la inauguración del servicio de ferrocarriles en México, en 1873, se inició el movimiento de viajeros por el territorio nacional y para 1911 la prensa mencionaba el gran potencial del país para el turismo (El Imparcial, 1911, febrero 17: 4). El estallido de la Revolución Mexicana en 1910 interrumpió 
esa posibilidad pero, al recuperarse cierta estabilidad política, la prensa insistió en el potencial del turismo como una vía para la recuperación de las finanzas nacionales, aprovechando la cercanía con los Estados Unidos (El informador, 1919, febrero 14: 2), siguiendo el ejemplo de países europeos como Francia que capitalizaba la industria de los visitantes para su reconstrucción después de Primera Guerra Mundial (El Informador, 1919, diciembre 5: 5).

Desde la década de 1920 los gobiernos posrevolucionarios se propusieron hacer del turismo una actividad que apoyara la reactivación de la economía nacional y la obtención de divisas, pero también un medio que permitiera fijar una imagen de México ante el mundo y un instrumento adicional que apoyara el desarrollo de las comunidades campesinas e indígenas. Para ello, se emprendieron planes y programas que incluyeron la construcción de una red carretera, campañas de propaganda, edición de guías y publicaciones especializadas, creación de organismo de financiamiento, comités de apoyo para el visitantes, además de una legislación de fomento al turismo y también para la protección de la imagen típica e histórica de poblaciones y ciudades, entre otras acciones (Mercado, 2016).

Una de esas estrategias fue la creación de una amplia legislación propicia para esa actividad. Un ejemplo es el "Acuerdo por el cual se previene que todo esfuerzo por el fomento y desarrollo del turismo en México es de forzosa protección por las autoridades" de 1929, que mencionaba ideas como las siguientes:

[...] es de la más alta importancia para la Nación promover y fomentar por todos los medios posibles la atracción del turismo [...], al ejemplo de otros países que han visto acrecentar sus recursos con los rendimientos de esta industria [...] qué México posee productos y bellezas naturales, monumentos arqueológicos y coloniales y excelentes condiciones climáticas, indudablemente capaces de provocar un intenso movimiento turístico. [...] Que al gobierno correspondía suprimir los obstáculos de orden administrativo que impedían a los turistas cruzar la frontera con toda clase de facilidades [...] Que ese esfuerzo exclusivamente oficial no lograría los resultados deseados si no contase con la entusiasta cooperación de las empresas particulares directamente beneficiadas, por lo que se estimó necesario crear la Comisión Mixta Pro-Turismo [...] (Periódico Oficial de Yucatán, 1929, julio 12: 2)

Posteriormente, se creó el Departamento de Turismo en 1933 y la Comisión Nacional de Turismo en 1934 (Periódico Oficial de la Federación, 2011, marzo 25). En el "Reglamento de la Ley General de Población vigente en su parte relativa al turismo" de 1937, se observa la clara intención del Estado para conducir esa actividad, encomendando al Departamento de Turismo valorar y operar propuestas de fomento turístico; asimismo, se indicaba la división del territorio nacional en 15 zonas para sistematizar la propaganda de los atractivos turísticos, normar y coordinar al sector público y privado, además de encauzar las corrientes de turismo nacional y extranjero (Periódico Oficial de la Federación, 1937, mayo 21).

Inclusive, en la iniciativa de creación del Instituto Nacional de Antropología e Historia (INAH) se argumentó los posibles beneficios del turismo, mencionando: “[...] Que además de los resultados científicos [...] que produce la exploración e investigación de los monumentos arqueológicos e históricos, puede también producir magníficos resultados materiales, en cuanto crea corrientes de turismo que influirán en la vida económica del país [...] (Olivé y Urteaga, 1988: 368-369).

Varios estado del país secundaron esas políticas: en Veracruz se creó un Departamento de Turismo en un esfuerzo conjunto entre el Comité local y las autoridades para informar y apoyar al viajero (El Informador, 1931, enero 3: 2); en Michoacán, el Departamento de Prensa y Turismo y Propaganda Comercial y Agrícola (Periódico Oficial del Estado de Hidalgo, 1931, abril 24: 156); y en Jalisco, la Dirección de Turismo y Propaganda, en cuyas oficinas el visitante podía encontrar todo tipo de información (El Informador, 1939, mayo 25:1).

Un caso destacado fue el estado de Morelos, en donde el gobernador Vicente Estrada Cajigal realizó entre 1930 y 1934 una verdadera cruzada para fomentar el turismo, impulsando la construcción de vías de comunicación y el embellecimiento de las poblaciones, lo cual fue secundado por el Ayuntamientos de Cuernavaca, capital de ese estado (Diario Oficial del Estado de Morelos, 1931, febrero 15: 4). Además, se estableció una agresiva política para atraer a los inversionistas, como puede apreciarse en el Decreto número 71, relativo al establecimiento de casino, hoteles, balnearios u otros centros de recreo en el estado. En ese decreto, además de facilidades para la inversión, se indicaron controles y normas para los sitios destinados a juegos de azar; igualmente se indicaba que en los establecimientos que se edificaran para ese propósito se debería de incluir una agencia de información para el visitante, una biblioteca con obras útiles para el fomento del turismo y periódicos, así como un salón destinado a una exposición permanente de los artículos que se producían en la república para darlos a conocer 
a los visitantes (Diario Oficial del Estado de Morelos, 1933, marzo 12: 1-3; 1933, mayo 7: 5). El propio gobernador Estrada Cajigal era el portavoz de esas políticas argumentando:

El Turismo ha sido considerado como fuente de inagotable influencia moral, siempre provechosa [...]. Los hombres de empresa tienen en Morelos amplísimo campo para desarrollar sus actividades con leyes que favorecen su crecimiento, que reducen los impuestos. En Morelos no conocemos barreras en materia de progreso y las que existían han desaparecido desde el primer año de su gobierno constitucional [...] (Diario Oficial del Estado de Morelos, 1933, mayo 28: 4).

El fomento del turismo fue un interés compartido por varios estados del país. En 1937, la prensa anunció la realización de una convención de los gobernadores de Jalisco, Sonora, Sinaloa, California y Arizona, entre otros estado de México y los Estados Unidos, la cual se efectuaría en Mazatlán para impulsar la construcción de la carretera Nogales-Guadalajara, con la participación de representantes del Comité de Turismo, asociaciones de automovilistas y de otras agrupaciones relacionadas con esa actividad (El Informador, 1937, febrero 3: 8).

En el marco de la Primera Convención de la Asociación Mexicana Automovilística (AMA) en 1940, el Comité Nacional de Turismo realizó sesiones previas durante el trayecto México, Toluca, Morelia y Guadalajara, a efecto de realizar una Convención Regional de Turismo, como precedente de un congreso Nacional de Turismo y, posteriormente, un Congreso Interamericano de Turismo. De esa forma, la Primera Convención Regional de Turismo se efectuó en Guadalajara en julio de 1940, con la presencia de los gobernadores del Estado de México, Michoacán y Jalisco; en ese evento se dio a conocer el programa del gobierno federal para el fomento del turismo, el programa de la Asociación Mexicana de Turismo, el plan de propaganda a la ruta México-Guadalajara, así como un programa regional de turismo para los estados de México, Michoacán y Jalisco, presentado por el Sr. Conrado Magaña, gobernador de Michoacán (El Informador, 1940, julio 2: 1 y 8).

\section{Asociaciones y Comités de Turismo}

La política desplegada por el gobierno mexicano fue propicia para la participación privada en el fomento del turismo, pero la fundación de agrupaciones privadas interesadas en promover esa actividad se remonta a los inicios del siglo XX. En 1907, la prensa anunció la formación del Touring Club Mexicano (TCM) por parte de personajes vinculados al primer círculo del poder político y económico en la capital del país (La Voz de México, 1907, abril 12: 3); para 1910, ese club planeaba actividades para promover el turismo y la apertura de caminos que facilitaran esa actividad (El Diario, 1910, marzo 21:8). En el inicio de la década de 1930, la Asociación Automovilística México-Americana estableció vínculos formales con organizaciones de los Estados Unidos como la American Automobile Association, para prestar ayuda mutua a sus agremiados en ambos países (El Informador, 1930, marzo 11: 2); en 1931 se fundó el Automóvil Club de México, integrado por políticos mexicanos y algunos diplomáticos acreditados en el país (El Informador, 1931, julio 19: 3) y, en 1932, se fundó la Asociación Mexicana Automovilística (AMA) en la ciudad de Monterrey (Berger, 2006: 30-32).

Las asociaciones de automovilismo tuvieron un efecto importante en la opinión pública al promover proyectos de gran envergadura, como fue la iniciativa para crear un Boulevard desde Canadá hasta la Patagonia, la cual tuvo una amplia difusión en la prensa nacional (El Informador, 13 de septiembre de 1929); la viabilidad de este proyecto se afianzó con las crónicas de viaje que los clubes automovilísticos de los Estados Unidos realizaron por México para explorar posibles rutas para hacer realidad esa iniciativa (El Informador, 1930, abril 28: 2). También se publicaron reportajes acerca de los viajes que realizaron automovilistas mexicanos hacia distintos puntos del país y de los Estados Unidos, como el efectuado de Acapulco a Texas en 1930 (El Informador, 1930, marzo 11: 2).

Además del interés por el turismo como un pasatiempo para los automovilistas, en México se formaron organizaciones privadas comprometidas con el fomento de esa actividad. Los ejemplos son diversos: en 1913 la Cámara de Comercio de Morelia manifestó en sus informes la necesidad de emprender un proyecto para fomentar el turismo en Michoacán, así como para extender las vías de ferrocarril hasta la costa del Pacifico (Semana Mercantil, 1913, marzo 10: 147); en 1922 se fundó la Asociación de Propietarios y Administradores de Hoteles, con motivo del asalto a unos turistas extranjeros que visitaban las grutas de Cacahuamilpa cercanas a Taxco (Mac Donald, 1981: 101); al pasar los años, se 
formaría la Asociación de Hoteleros en 1941 (Mac Donald, :101-102); igualmente, en 1928, se fundó la Asociación Mexicana de Restaurantes Asociación Civil (Mac Donald, 1981: 107).

Los organismos más activos e influyentes en esta actividad fueron los Comités Pro-turismo. En 1928, en Baja California Sur, se publicó la nota titulada "Importancia económica del turismo", en donde se mencionaba que en el año anterior los turistas estadounidenses habían dejado un derrama económica de 85 millones de dólares en Europa, de 197 millones de dólares en Canadá y de 6 millones de dólares en México. Ante tales cifras, se indicaba la intensa campaña desplegada por Canadá y las facilidades otorgadas a sus visitantes, así como la siguiente reflexión: "[...] Si se logra dar al turismo en México el mismo incremento que se ha llegado a darle en el Canadá, los ingresos por este concepto superarían a los que produce la industria petrolera [...] las oportunidades que ofrece México, tanto al que viaja por placer como al hombre de negocios, no tienen igual en América (Periódico Oficial del Estado de Baja California, 1928, octubre 24: 2 y 5). Ante esas expectativas, el Gobierno de México actuó y en su informe ante el Congreso, en 1929, el presidente Portes Gil mencionó:

La intensa corriente de turismo [...] puso de manifiesto la necesidad de [...] mayor atención a esta nueva fuente de prosperidad y para ello se ha establecido la Comisión Mixta Pro-Turismo integrada [...] inició la formación de juntas similares en todas y cada una de las capitales de los Estados, así como en otras poblaciones de importancia [...] contando actualmente con veinticuatro Comités locales [...] Su labor inmediata fue la de suprimir todas aquellas disposiciones de orden administrativo que se oponían a la fácil entrada del turista [...] (Mac Donald, 1981: 107).

En los años subsecuentes, los Comités Pro Turismo se afianzaron en el país. En el caso de Tamaulipas, el gobierno del estado recomendó a los presidentes municipales instalar una Junta Local de Turismo con motivo de la apertura de la carretera México-Laredo (Periódico Oficial del Estado de Tamaulipas, 1930, diciembre 24: 1041). Asimismo, la prensa difundió la fundación de Comités Pro Turismo en Guadalajara (El Informador, 1929, julio 20: 6); en la ciudad de Oaxaca (El Informador, 1930, enero 23 : 2); en Mérida (El Informador, 1930, noviembre 27: 2); en Cuyutlán, Colima (El Informador, 1932, enero 29: 1); en Campeche (El Informador, 1933, septiembre 28: 1); en la ciudad de Colima (Periódico Oficial del Estado de Colima, 1933, octubre 28: 371), ciudad donde se volvió e integrar ese organismo en 1935 junto con otro similar en Manzanillo (El Informador, 1935, diciembre 19: 8); así como en Mazatlán en 1939 (El Informador, 1939, mayo 16: 5), entre otros casos. Esta política tuvo continuidad y, en 1936, el presidente Cárdenas informaba al Congreso: "[...] Por decreto de 20 de abril, se creó el departamento de Turismo. Se establecieron comités Pro-Turismo en las poblaciones más importantes que toca la carretera México-Laredo y en otros estados" (Mac Donald, 1981: 78).

En realidad, los comités pro turismo creados desde la iniciativa privada fueron anteriores a la iniciativa pública. En 1923 ya se había fundado el Comité Pro-Guadalajara, con el propósito de fomentar el turismo en todo el estado de Jalisco, así como para hacer esa ciudad más atractiva para los turistas y los empresario (El Informador, 1923, marzo 25: 1); entre sus primaras acciones se promovió un concurso para premiar al mejor proyecto de propaganda para lograr esos objetivos y la cual debería de abarcar "todo el mundo" (El Informador, 1923, abril 23:1).

En 1929, y siguiendo las directrices oficiales, se fundó el Comité Pro Turismo de Guadalajara y se integró su primera directiva (El Informador 1929, julio 20: 6); durante los siguientes tres lustros la prensa local difundió asiduamente las iniciativas, acciones y obras promovidas por ese organismo, el cual tuvo continuidad con cambios en las directivas y también en el nombre, designándose como Comité de Turismo (El Informador, 1933, junio 23: 4) o Comité Cívico Pro Turismo (El Informador, 1940, abril 25: 2). Las acciones de ese organismo fueron variadas y, de acuerdo con las notas de prensa, giraron en torno a temas como la formación de cartas geográficas; colaboración en la organización de ferias y festividades de Carnaval, la feria de Todos los Santos o de Navidad; organización de carreras de automóviles; organización y difusión de excursiones locales y foráneas; apoyo al visitante con información; reglamentación de guías de turistas, organización de estudios y de un colegio para guías de turistas; organización de recepciones a excursiones de nacionales y extranjeros; conferencias sobre turismo; gestión de mejoramiento de carreteras y comunicaciones en general; patrocinio de propaganda y reportajes en el país y en el extranjero; organización de agencias de turismo; edición de guías, folletos y planos de obsequio; gestión para el retiro de mendigos y de puestos ambulantes del centro de la ciudad; especificaciones para construcción de sanitarios; patrocinio de tomas fotográficas; reglamento de mendicidad; impulso a la industria alfarera; promoción para la construcción de un campo de golf; 
aseo de calles y saneamiento de atractivos naturales como el Salto y Juanacatlán o el acondicionamiento del mirador de la Barranca de Oblatos; entre otras muchas actividades.

\section{Una imagen urbana para el turismo}

El aspecto de las poblaciones, la conservación de las bellezas naturales o las condiciones de higiene fueron, entre otros temas, motivo de atención por parte del gobierno y de las asociaciones civiles, ya que se percibían como un factor importante para atraer a los turistas.

El plan carretero iniciado en 1925 tuvo éxito, pero la construcción de vías terrestres alteró el entorno natural, lo cual fue señalado en medios de difusión académicos:

Se acerca ya el día en que las autoridades se van a ver precisadas a tomar medidas enérgicas en defensa de nuestros paisajes [...] Díganlo si no los montones de detritos que han quedado al lado de la nueva carretera de Cuernavaca [...] sobre las estribaciones del Ajusco, horrendas cicatrices que claman por un manto arbolado; y díganlo también los anuncios que [...] sobre [...] el camino de Puebla, anuncios que son una vergüenza nacional. Nadie negará que se exija una intervención inmediata por parte de las comisiones interesadas [...]. A propósito cabe reproducir un informe que acaba de ser sometido a la Secretaría de Relaciones

Exteriores por el Cónsul de México en Yokohama, don Manuel Tello [...] (Universidad, 1931, enero 1: 268).

En el informe mencionado anteriormente, el cónsul Manuel Tello hacía referencia a las leyes para proteger las bellezas naturales en Japón, recomendando medidas similares en México debido a la posibilidad del aprovechamiento turístico de esos recursos y la afectación del paisaje (Universidad, 1931, enero 1: 268). Pero igualmente un motivo de preocupación fueron las poblaciones de la frontera con los Estados Unidos, ya que en muchos casos sus condiciones eran deplorables y la prensa clamaba por su mejora (El Informador, 1929, septiembre 13:3).

El desarrollo de equipamiento turístico en ciudades de la frontera como Tijuana fue dominada por la construcción de instalaciones que pretendían satisfacer la expectativa de los extranjeros acerca de una arquitectura y un ambiente "mexicano"; tal fue el caso del complejo "Agua Caliente" que evocaba más bien a la arquitectura andaluza, incluyendo decorados y elementos de la arquitectura morisca. En la ciudad de Cuernavaca, el impacto del turismo en la transformación urbana fue relevante, acerca de lo cual la prensa oficial señalaba que "[...] Se están construyendo casas que son verdaderos palacios y que valen muchos millares de pesos. Terrenos que hasta hace tres años eran basureros, están hoy convertidos en colonias de refinado gusto modernista" (Periódico Oficial de Morelos, 1933: marzo 19:3). El derrotero que seguían la arquitectura y la imagen urbana de sitios como Tijuana y Cuernavaca fue criticado abiertamente en un artículo con el título de "La tijuanización de Cuernavaca", en el cual se lamentaba el detrimento del aspecto tradicional de esta última ciudad en aras del progreso y la atracción de visitantes e inversionistas (Mapa, 1936, octubre: 21)

En ese contexto se promulgaron leyes federales para salvaguardar el aspecto de ciudades históricas y poblaciones típicas del país, como fueron la "Ley sobre protección y conservación de monumentos y bellezas naturales" de 1930, así como la "Ley sobre protección y conservación de monumentos arqueológicos e históricos, poblaciones típicas y lugares de belleza natural" de 1934. En cuanto al patrimonio natural, el Desierto de los Leones, en el Estado de México, fue designado como Parque Nacional en 1917, siendo el primero de este tipo; durante el gobierno del presidente Cárdenas, un total de 39 sitios naturales fueron incorporados a la protección legal (CONANP, 2019). Por su parte, el Lago de Pátzcuaro fue declarado como propiedad de la Nación desde 1919 (Periódico Oficial del Estado de San Luis Potosí, 1919, mayo 14: 1), en tanto que en el decreto de creación del Parque Nacional del Nevado de Colima, se indicaba que este sitio sería un "[...] atractivo poderosísimo para el desarrollo del gran turismo" (El Informador, 1936, septiembre 25: 1).

En el estado de Guerrero se promulgó la "Ley para la conservación de la ciudad de Taxco de Alarcón" de 1928 y en Michoacán la "Ley de Protección de Inmuebles Históricos o Artísticos" de 1930 (Tavera, 2002: 383-388). Con la promulgación de la ley federal de 1930, antes mencionada, el gobierno de la república solicitó a los gobiernos de los estados promulgar leyes locales semejantes (Mercado 2013: 147), por lo cual en Michoacán se expidió la "Ley Estatal sobre Protección y Conservación de Monumentos y Bellezas Naturales" (Periódico Oficial del Estado de Michoacán, 1931, junio $1^{\circ}$ ) e igualmente se promulgaron normas similares en el estado de Aguascalientes (Periódico Oficial del Estado de Aguascalientes, 1931, mayo 10), Colima (Periódico oficial del Gobierno Constitucional de Colima, 1931, julio 18), Puebla 
(Periódico Oficial del Estado de Puebla, 1932, octubre 14), Sonora (Boletín Oficial del Gobierno de Sonora, 1931, mayo 20), o Tamaulipas (Periódico oficial del Estado de Tamaulipas, 1931, abril 30), entre otros. Asimismo, en 1938 se expidieron las "Instrucciones relativas para las construcciones en las avenidas 20 de Noviembre y Francisco I. Madero en Jiquilpan, Michoacán” de 1938. Por su parte, en las leyes de creación de las Juntas de Mejoras Materiales, también se hacía alusión a la necesidad de dar a las poblaciones un aspecto adecuado para el turismo, como fue el caso del estado de Coahuila (Periódico Oficial del Estado de Coahuila, 1944, mayo 24: 17; septiembre 6: 6-7).

En el ámbito federal, tanto el "Reglamento de la Ley General de Población vigente en su parte relativa a turismo", de 1937 (Periódico Oficial de la Federación, 1937, mayo 21), como el "Acuerdo relacionado con el fomento y desarrollo del turismo nacional e internacional" de 1940 (Periódico Oficial de la Federación, 1940, noviembre 27), incluían la indicación de salvaguardar escrupulosamente el aspecto del carácter típico de las poblaciones, así como los usos y costumbres de sus pobladores.

\section{Los servicios para el visitante: hospedaje y guías de turistas}

La regulación y formación de los guías de turistas fue un tema de atención por parte del ámbito público y privado. En diversos estados del país se promulgaron reglamentos para la autorización de guías, como fue Querétaro (Periódico oficial del Estado de Querétaro, 1934, enero 18: 11 y 12), Chihuahua (Periódico Oficial de Estado de Chihuahua, 1933, julio 8: 4-6), Morelos (Diario oficial del Estado de Morelos , 1933, julio 30: 1.2), Colima (Periódico Oficial de Estado de Colima, 1933, agosto 12: 263), Distrito Federal (Periódico Oficial del Estado de Guerrero, 1934, abril 4: 3), o Jalisco (EI Informador, 1934, agosto 29: 2). El contenido de estos reglamentos siguió un modelo formulado a nivel federal, el cual fue copiado casi literalmente aunque con ciertas adecuaciones en cada caso.

En Jalisco se anunció la creación de una Escuela para Guías de Turistas por parte del Comité de Turismo en 1937 (El Informador, 1937, agosto 20: 4) y, en septiembre de ese mismo año, se dio a conocer el contenido del programa de las clases a impartir (El Informador, 1937, septiembre 1: 3 y 6; septiembre 4: 8; septiembre 5: 14 y 16). Por su parte, el "Plan de Estudios para Guía de Turistas en el estado de Puebla, formulado por el Departamento de Turismo del Gobierno local y aprobado por el Gobernador Constitucional", Maximino Ávila Camacho, incluía los apartados de Historia, Etnografía, Geografía, Arqueología, Arte y arquitectura colonial, Folklore, Comunicaciones, así como Turismo, con una descripción de las rutas turísticas del estado de Puebla (Periódico Oficial del Estado de Puebla, 1940 junio 16: 1-22).

El servicio de hospedaje mereció la atención de la prensa, señalando que los establecimientos de hospedaje eran, en general, escasos y de mala calidad, según se deja ver en diversas notas periodísticas. En el viaje automovilístico Acapulco-Texas, emprendido por el Sr. A.L. Rodríguez y el matrimonio Johnson, los viajeros se quejaron por la desatención de los hoteles de las poblaciones que tocaban a su paso (El Informador, 1930, marzo 11: 2). Por su parte, en la excursión del Automóvil Club del Sur de California, sus integrantes calificaban los hoteles como "[...] primitivos ciertamente, pero [...] llenos de comodidades y saturados con una magnífica atmosfera [...]" (El Informador, 1930, abril 28: 2). Las editoriales de la prensa repetían con frecuencia la necesidad de contar con buenos hoteles, entre otras condiciones necesarias para atraer a las grandes corrientes de turistas (El Informador, 1929 noviembre 6: 3 y 6; 1931, mayo 7: 3), lo cual fue reiterada en el proyecto para aumentar el turismo en México presentado por el periódico New York Times al Secretario de Hacienda y Crédito Público, Luis Montes de Oca (El Informador, 1931, junio 28:1).

En ocasiones, la oferta de hospedaje existente no satisfacía ni siquiera la demanda interna. En las vacaciones de primavera de 1932, se reportaron más de 60 mil turistas que llegaron al estado de Morelos y cientos de visitantes a la ciudad de Cuautla no encontraron hospedaje, teniendo que alojarse en casas particulares e inclusive tuvieron que dormir en parques y jardines en la ciudad (Periódico Oficial del Estado de Morelos, 1932, abril 17:3). En 1937, con motivo de los preparativos de la excursión de primavera en el mes de mayo, el puerto de Mazatlán esperaba más de 10 mil turistas y el Ayuntamiento anuncio que construiría por su cuenta dos mil catres, previendo espacios, además de ropa de cama y mobiliario para los visitantes que lo requirieran (El Informador, 1937, abril 2: 3).

Tanto las organizaciones privadas como las autoridades emprendieron iniciativas para promover la construcción de hoteles, por ejemplo, el Comité Pro Turismo de Guadalajara incluyo en su organización un subcomité de hoteles (El Informador, 1929 agosto 7: 1). El gobierno del estado de Hidalgo exhortó aprovechar la carretera México-Laredo que pasaría por su territorio, recomendando "[...] cumplir la 
ley de turismo, crear un comité pro-turismo, apoyar la actividad y difundir el turismo; crear hoteles, cuidar los atractivos y el aspecto típico. (Periódico Oficial del Estado de Hidalgo, 1930, noviembre 24: 1). Por su parte, el gobierno de la república creó en 1935 la institución de Crédito Hotelero, a efecto de apoyar a los inversionistas del sector (Mac Donald, 1981: 119).

El movimiento de turistas rebasaba la capacidad de alojamiento, lo cual puede apreciarse en las declaraciones del Sr. Francisco Trejo, Jefe de Población de la Secretaría de Gobernación, con motivo de la Convención de la AMA en 1940:

El año pasado la derrama del turismo nacional tuvo un equivalente de trescientos millones de pesos, en este año se espera [...] sobre pase a quinientos millones [...]. Se está haciendo una campaña para crear alojamientos adicionales: $1^{\circ}$.- sobre la base de que las familias presten locales para los turistas; $2^{\circ}$.- que se aumente el número de hoteles y casas de hospedaje [...] $3^{\circ}$.- para lograr que numerosos cascos de haciendas abandonadas que reúnen condiciones turísticas excepcionales sean debidamente acondicionadas. En la actividad que demuestren los particulares para el acondicionamiento de alojamiento, radica la esperanza de que en el año próximo el turismo [...] de un salto [...]. Las ciudades y regiones que los ofrezcan -cómodos y confortables- contarán con ingresos extraordinarios que aumentarán las oportunidades de beneficio [...] de esta nueva industria que tiene clientes por centenares de miles prontos a venir [...] (El Informador, 1940, julio 2:8).

En un artículo publicado en febrero de 1940 se hacía mención de la exitosa temporada decembrina de 1939 en la Ciudad de México, en donde los informes oficiales registraban 10,000 turistas y un movimiento diario de 500 visitantes, así como la insuficiencia de hospedaje, señalando que se había dado el caso en algunos días en los cuales más de 2,000 turistas se quedaron sin alojamiento. En el texto se mencionaba que en Guadalajara se advertía el riesgo de un panorama similar ante la expectativa de la llegada de excursiones de visitantes norteamericanos en los primeros meses de 1940, una excursión de Semana Santa de la Sociedad Mutualista de Monterrey -que contaba con 6,000 agremiados-, así como el Campeonato de Futbol que se realizaría en esa misma temporada. Ante esa perspectiva, el Comité de Turismo, siguiendo las instrucciones del Departamento de Turismo, implementó el programa de "Posada Familiar" invitando a la población que tuviera las facilidades necesarias para que alojara turistas en sus hogares, para lo cual se recomendaba anunciarse en la sección del "Aviso de ocasión" de la prensa local (El informador, 1940, febrero 22: 6).

\section{La propaganda de viajes y excursiones}

Con el inicio de las operaciones del ferrocarril en el territorio mexicano, se empezaron a promover las excursiones. Desde fines del siglo XIX las notas de prensa mencionaban excursiones de extranjeros que visitaban sitios como la Ciudad de México (El Correo Español, 1891, febrero 21: 3; La Voz de México, 1897, febrero 10: 3) o el Puerto de Progreso, Mérida y las "ruinas" aledañas (El Tiempo, 1910, febrero 7: 8); grupos de congresistas de eventos científicos y académicos que acudían a lugares como Teotihuacán o Xochimilco (El Correo Español, 1895 noviembre 3: 2; noviembre 13: 2), o bien excursiones que tocaban sitios como Mitla y Puebla (La Voz de México, 1895, noviembre 15: 2).

A través de anuncios la prensa promovía, por ejemplo, excursiones para la Semana Santa desde la capital del país hasta las ciudades de Celaya, Guanajuato, León y Guadalajara, al tiempo que se mencionaban una "extraordinaria rebaja" en los precios de los pasajes en las distintas clases disponibles en el ferrocarril, señalando que "[...] en las ciudades expresadas, con especialidad en Guadalajara, las funciones religiosas de estos días celébranse con gran solemnidad [...]" (La Voz de México, 1892, abril 9: 2).

Por su parte, los peregrinos que acudían al santuario de la Virgen de Guadalupe en la capital del país, también hicieron uso de los nuevos medios de transporte para acudir a ese sitio de fe (La Voz de México, 1896, noviembre 13: 2). En algunos casos la prensa asoció las celebraciones religiosas con el turismo, tal fue el caso de las tradicionales verbenas de Todos Santos y Finados en Guadalajara, donde los reportajes mencionaban la relativa alegría de esa celebración fuera de la solemnidad de los templos, así como el incremento de ventas en los puestos de frutas y juguetes debido al contingente de excursionistas que habían visitado la ciudad (El Informador, 1932, noviembre 3: 1). Asimismo, con motivo de las fiestas de Nuestra Señora de Guadalupe en Jocotepec, Jalisco, la prensa reportó un "[...] numeroso contingente de turistas que dio mayor realce con su presencia a los ritos religiosos [...]" (El Informador, 1939, julio 12:4). 
Con motivo del IV centenario de las apariciones de la Virgen de Guadalupe, el Subsecretario de Gobernación de México anunció que no se impediría la entrada al país de peregrinos católicos extranjeros que visitaran al país como turistas, en tanto que no contravinieran las leyes vigentes del país (El Informador, 1931, noviembre 7: 1), lo cual deja entrever que el viaje asociado al culto religioso se prefiguró desde esa época como una variante más de la actividad turística.

Durante la década de 1930 las notas de prensa difundieron asiduamente la realización de diversas excursiones de visitantes nacionales y extranjeros. Un caso relevante fue la convención internacional de Rotarios, realizada en la ciudad de México y a la cual acudieron 5,303 socios afiliados a 2,670 clubes de 72 países, lo cual mereció varias menciones en la prensa nacional y local, ya que varios grupos visitaron ciudades del interior del país como Guadalajara y Mazatlán (El Informador, 1935 junio 13: 3; junio 22 : 1). Igualmente, se difundió la visita de un grupo de agentes de viajes de Texas (El Informador, 1935 septiembre 28: 3 y 5); otra excursión organizada por la organización Press Association, encabezada por el ex gobernador de California W. Richardson; así como tres grandes contingentes procedentes de Chicago que visitarían Guaymas, Mazatlán, Guadalajara, Pátzcuaro, Uruapan, Cuernavaca, Orizaba, Guanajuato y León (El Informador, 1936, febrero 7: 3), entre otras diversas notas que tocaban ese mismo tema.

A través de la prensa se puede confirmar un intenso movimiento de turistas nacionales que recorrían el país, la cual difundía eventos como la excursión Carta Blanca al puerto de Veracruz (El Informador, 1930, octubre 20:1); la visita a rutas como la de Uruapan, Pátzcuaro y Morelia (El Informador, 1932 marzo 2: 6), viajes a Guadalajara (El Informador, 1932, octubre 16: 1) o a la Ciudad de México, en donde se destacó la llega de 1,200 visitantes procedentes de Nuevo León (El Informador, 1934, julio 3: 3; julio 30: 1); en tanto que en 1937 se mencionaba que habían llegado 10 mil turistas a Mazatlán (El Informador, 1937, abril 2:3). Asimismo, a través de esas notas se pueden identificar algunos de los destinos turísticos de la época: las playas de Cuyutlán, el Lago de Pátzcuaro, Morelia, Uruapan, Mazatlán, Santiago, Miramar, Colima, Mazatlán, la Ciudad de México, Teotihuacán, Guadalajara, el Salto de Juanacatlán, Chapala, Barra de Navidad, el Volcán de Colima, las Grutas de Cacahuamilpa, Veracruz, Cuernavaca, Cuautla, así como los balneario del estado de Morelos, o las ciudades de Puebla, Oaxaca, Mérida y Acapulco, entre otros sitios.

Por otra parte, se realizaban eventos que atraían visitantes a diversas ciudades del país como fueron la convención de agentes de viajes de pasajes de ferrocarril realizada en 1924, visitando la capital, así como Guadalajara y Chapala (El Informador, 1925, abril 24: 1); el Tercer Congreso Nacional de Sociedades Mutualistas en la ciudad de Puebla (El Informador, 1934, septiembre 22: 2); o la primera convención de la AMA en Guadalajara (El Informador, 1940, julio 2: 1 y 8).

Un motivo para la organización de excursiones fueron los aniversarios de la fundación de ciudades como Guadalajara que celebró su IV Centenario (El Informador, 1940, febrero 18: 15); o bien el vigésimo quinto aniversario de que Torreón fue elevada a la categoría de ciudad (Diario Oficial del Estado de Morelos, 1932, julio 17: 4).

\section{La estadística del turismo}

Un aspecto que cobró un interés creciente fue el conteo de visitantes. En 1934 las noticias mencionaban que, de acuerdo con datos de la Secretaría de Economía, en 1933 habían arribado 11 mil turistas al país, quienes habían gastado aproximadamente cinco millones de dólares (El Informador, 1934, enero 11: 1). Para calcular el número de turistas se acudía a las cifras de boletos vendidos por los ferrocarriles y al movimiento de automóviles; por ejemplo, en marzo de 1934 las noticias mencionaban la "inusitada corriente de turismo" con motivo del período vacacional en la cual Ferrocarriles Nacionales (FCN) vendió 34,567 boletos de excursión con tarifa reducida, las agencias de viajes comercializaron 16,000 boletos de excursión, en tanto que 18,000 automóviles particulares y de alquiler habían salido de la Ciudad de México (El Informador, 1934, marzo 28: 1).

En el estado de Morelos, el Periódico Oficial daba a conocer el número de visitantes que recibían ciudades como Cuernavaca y Cuautla, así como los balnearios que eran un sitio de recreo favorito de los habitantes de la cercana capital del país. Así, se indicaba el arribo de 27,000 turistas en 1930 (Diario Oficial del Estado de Morelos, 1931, enero 18: 3); posteriormente se hizo una corrección a ese dato y se mencionaba que en 1930 se registraron 100,500 visitantes, una cifra de 247,235 viajeros en 1931 y de 685,025 durante 1932, entre turistas, hombres de negocios, políticos y hombres de ciencia, predominándolos los primeros (Diario Oficial de Estado de Morelos, 1933, marzo 19: 1, 3 y 4). 
Algunas notas magnificaban las cifras señalando, por ejemplo, un "asombroso" contingente de 21,720 turistas que llegaron en marzo a Cuernavaca y 7,200 a Cuautla, que visitaron principalmente el Balneario Agua Hedionda, con un total de 22,900 viajeros al estado y de los cuales el 50\% eran extranjeros (Diario Oficial del Estado de Morelos, 1931, abril 19: 3). Para mayo de 1931 se indicaba una cifra record de turistas con el arribo de 22,700 personas a Cuernavaca y de 10,895 a Cuautla (Diario Oficial del Estado de Morelos, 1931, junio 17: 1). A fines de ese año, se mencionaba que Morelos era la "Meca del turismo" con 4,460 turistas en Cuernavaca y 8,040 en Cuautla durante el mes de noviembre (Diario Oficial del Estado de Morelos, 1931, diciembre 20: 1 y 4).

El gobierno de Morelos señalaba la metodología de su acuciosa estadística, para lo cual se contabilizaban los automóviles que circulaban por las carreteras de ese estado; por ejemplo, en febrero de 1932 se registraron 64,472 automóviles que entraron por la carretera México-Acapulco (Diario Oficial del Estado de Morelos, 1932, marzo 13: 3). Esas cifras eran la base para estimar el número de visitantes: "[...] durante el mes de diciembre pasado, visitaron el estado veintiséis mil turistas, tomando en cuenta únicamente coches con cinco pasajeros cada uno, en número de cinco mil doscientos automóviles en puntos de entrada como Cuernavaca y Cuautla nada más. Están excluidos de este cálculo los camiones, así como el servicio ordinario de coches en que viajan personas radicadas en el estado [...]" (Diario Oficial del Estado de Morelos, 1931, enero 18: 1)

En el caso de Jalisco, el Comité de Turismo se dio a la tarea de formar una estadística de visitantes, para lo cual se consideraba el número de vehículos que transitaban cada mes por puntos específicos de las principales carreteras de Jalisco (El Informador, 1934, junio 11: 3), con base en lo cual en los siguientes año se publicaron las cifras mensuales obtenidas.

Como puede apreciarse, en materia de estadística los esfuerzos fueron aislados y sin continuidad, no obstante, el conteo de visitantes y su difusión en la prensa nacional fue un aliciente importante para fomentar esa actividad en el país.

\section{Reflexiones finales}

En la sucinta revisión de la difusión del turismo y sus efectos en la provincia de México durante las primeras décadas del siglo XX, se advierte que la acción de los gobiernos posrevolucionarios se puede inscribir en el actual concepto de política pública, entendida como el conjunto de objetivos colectivos "[...] considerados necesarios o deseables por medios y acciones que son tratados, por lo menos parcialmente, por una institución u organización gubernamental con la finalidad de orientar el comportamiento de actores individuales o colectivos para modificar un situación percibida como insatisfactoria o problemática" (Roth, 2009: 140).

Si como objetivo del fomento al turismo se tuvo la mejora de las finanzas, la captación de divisas y el desarrollo de las comunidades marginadas, los planes y programas oficiales tuvieron la virtud de crear condiciones propicias para una inicial forma de asociación público-privada al conjugar intereses compartidos. Los comités pro-turismo fueron eficientes vehículos para desarrollar la vocación turística de ciertas ciudades y regiones del país, así como para involucrar a las organizaciones sociales y a la población local en actividades que hicieran de la visita una experiencia agradable para el visitante. En este último aspecto, la prensa jugó un papel preponderante al difundir las actividades, las estadísticas de visitantes y los avances en el desarrollo del turismo, fijando en el imaginario colectivo la importancia de esa actividad para incorporar a las regiones y localidades al progreso.

Un aspecto interesante es observar cómo algunos destinos que en su momento fueron verdaderos atractivos turísticos, como fue el caso de Cuyutlán en Colima, no lograron consolidar esa condición; en tanto otros, como Cuernavaca y Chapala, fueron además sitios de residencia de expatriados Ettinger (2018); o bien los centros históricos de ciudades como Pátzcuaro y Morelia que, gracias a una legislación protectora de su imagen urbana, se afianzaron como espacios para el turismo (Mercado, 2013). Lo anterior muestra que la consolidación de los destinos turísticos solo es posible mediante esfuerzos sostenidos por largos períodos de tiempo y con una continuidad que permita generar una imagen turística en la cual confluyan las aspiraciones de las comunidades y las expectativas del visitante.

Por otra parte, ante la necesidad de incrementar la oferta de hospedaje se buscaron alternativas que pueden considerarse un antecedente remoto de modalidades actuales como es la vivienda turística o la adecuación de haciendas como espacio para el visitante; pese a lo anterior, el potencial de éstas últimas aún no ha sido explotado en su totalidad. 
En la regulación y formación de guías de turistas se advierte la confección de un guión abreviado de la versión oficial de la historia, apegada a la ideología de la Revolución Mexicana, basada en la idea de un pasado indígena glorioso y lo criollo como sinónimo de lo mexicano. El peso de la información acerca de la arquitectura prehispánica y del virreinato en el contenido de los cursos para formación de guías son buena muestra de ese trasfondo ideológico.

Los rasgos de cultura que caracterizaban al país fueron motivo de propaganda y objeto de regulación legal mediante leyes tendientes a mantener una imagen urbana dispuesta para el turismo. No obstante, esa voluntad tenía implícito un dilema que subsiste hasta la actualidad, al tratar de incorporar al progreso a poblaciones y ciudades a la vez se intentaba mantener sus rasgos urbanos y arquitectónicos, así como sus formas de vida ancestrales que fueron y siguen siendo el principal atractivo de los pueblos "mágicos" y de centros históricos de origen virreinal. Un aspecto adicional es que las intervenciones realizadas en las ciudades y poblaciones mexicanas en las primeras décadas del siglo XX, plantean un serio cuestionamiento acerca de la supuesta autenticidad de esos sitios, al comprobar que el aspecto típico o colonial que ahora se defiende fue, en su momento, inducido por la legislación y por un interés netamente turístico hace menos de una centuria.

La legislación de la época de estudio permite advertir la prefiguración de conceptos que en la actualidad se presentan como una opción para salvaguardar el patrimonio cultural y natural. En particular, se mencionaba la idea de acentuar y preservar "[...] las características típicas del país y los usos y costumbres de valor estético y de significación espiritual de nuestro pueblo [...] el ambiente típico de la ciudad y de sus alrededores, mediante los reglamentos y normas de planificación, zonificación y construcción urbanas, y de preservación de las bellezas naturales; [...] (Diario Oficial de la Federación, 1940, noviembre 27), lo cual se acerca al actual concepto de paisaje cultural, que tiende a integrar en una visión unitaria la conservación del legado cultural y natural como producto de la evolución de las comunidades insertas en un entorno natural.

El desarrollo del turismo en México durante las primeras décadas del siglo XX fue un proceso que si bien siguió los modelos internacionales para atraer al turismo estadounidense, abrevó tanto de la circulación de ideas como de las particularidades de las regiones y localidades del país. En esa experiencia se advierte que la consolidación de los destinos turísticos son producto de un esfuerzo sostenido por amplios períodos de tiempo que deviene en la generación de una imagen turística característica; una construcción social en la cual confluyen aspectos de muy diversa índole, como pueden ser un emplazamiento geográfico, un legado cultural producto del propio devenir de la sociedad receptora, así como intereses económicos e ideológicos determinados por un contexto histórico; proceso en el cual también confluye necesariamente la mirada del otro, del visitante (Mercado, 2018: 57).

En suma, el desarrollo del turismo en las distintas regiones, estados y ciudades del país durante la época de estudio fue un proceso diferenciado, condicionado por los potenciales atractivos que podían ofrecerse al visitante; las condiciones de las comunicaciones apenas en construcción; la disponibilidad de servicios para el viajero en ferrocarril y en automóvil, de hospedaje y alimentación; así como por las iniciativas públicas y privadas que generaban en mayor o menor medida las condiciones para el fomento de esa actividad productiva.

\section{Bibliografía}

Alvarado I. y López, A. 2018. Turismo, patrimonio y representaciones espaciales. Tenerife, Pasos Edita. Berger, D. 2006. The Development of Mexico's Industry: Pyramids by Day, Martinis by Night. Nueva York: Palgrave Macmillan.

CONEVAL 2015. Medición de la pobreza en México y en las entidades federativas. Recuperado de file:///F:/2016/PROYECTO\%202016-2017/Pobreza\%202014_CONEVAL_web.pdf, 21 de noviembre de 2017.

CONANP 2019. Listado de las Áreas Naturales Protegidas de México (LISTANP). Recuperado de http:// sig.conanp.gob.mx/website/pagsig/listanp/, 23 de septiembre de 2019.

Ettinger, C. 2018. La arquitectura mexicana desde fuera. Episodios en la construcción de un imaginario. México, M.A. Porrúa.

INAH 2017. Geoportal. Recuperado de http://www.geoportal.inah.gob.mx/?page_id=363

Mac Donald, E. 1981. Turismo, una recapitulación. Historiografía de conceptos pronunciados por gobernantes mexicanos desde 1823. México: Editorial Bodoni.

Mapa 1936 octubre. 
Mercado, E. 2013. Ideología, Legislación y Patrimonio Cultural. Legislación local para la conservación del patrimonio urbano-arquitectónico en Morelia, 1825-2001. Morelia: Secretaría de Cultura de Michoacán.

Mercado, E. 2016. Patrimonio cultural y turismo en el México pos-revolucionario. Pasos. Revista de Turismo y Patrimonio Cultural, 14 (4), 1027-1040.

Mercado, E. 2018. El turismo y su impacto en las primeras décadas del siglo XX: la perspectiva de la prensa de la época. Pasos. Revista de Turismo y Patrimonio Cultural, 16 (3), 671-683.

Olivé, J. y Urteaga, A. 1988. INAH, una historia. México: INAH.

Planificación 1928. 10, 15-16.

Plan Nacional de Desarrollo 2019-2024 2019. Recuperado de https://lopezobrador.org.mx/wp-content/ uploads/2019/05/PLAN-NACIONAL-DE-DESARROLLO-2019-2024.pdf

Rodríguez, V. 1998. Turismo urbano y cultural en internet. En Manuel Marchena (ed.) Turismo urbano y Patrimonio Cultural; una perspectiva europea. Sevilla: Diputación de Sevilla, 55-79.

Roth, A. 2009. Politicas públicas. Formulación, implementación y evaluación. Bogotá: Aurora.

Tavera, X. 2002. Recopilación de Leyes y Decretos del H. Congreso de Michoacán. Continuación de la iniciada por Don Amador Coromina, Tomo L. Morelia: H. Congreso del Estado de Michoacán.

\section{Hemerografía}

Boletín Oficial del Gobierno de Sonora

(1931). Mayo 20.

Diario Oficial del Estado de Morelos

(1931). Febrero 15, julio 18.

(1933). Marzo 12, mayo 7, mayo 28, julio 30.

Diario Oficial de Estado de Colima

(1933). Agosto 12, octubre 28.

El Correo Español

(1891). Febrero 21.

(1895). Noviembre 3, noviembre 13.

El Diario (1910). Marzo 21.

El Imparcial (1911). Febrero 17.

El Informador

(1919). Febrero 14, diciembre 5.

(1925). Abril 24.

(1929). Julio 20, agosto 7, septiembre 13, noviembre 6 .

(1930). Enero 23, marzo 11, abril 28, octubre 20, noviembre 27.

(1931). Enero 3, mayo 7, junio 28, julio 19, noviembre 7.

(1932). Enero 29, marzo 2, octubre 16, noviembre 3.

(1933). Junio 23, septiembre 28.

(1934). Enero 11, marzo 28, junio 11, julio 3, julio 30, agosto 29, septiembre 22.

(1935). Junio 13, junio 22, junio 23, diciembre 19.

(1936). Febrero 7, septiembre 25.

(1937). Febrero 3, abril 2, agosto 20, septiembre 1, septiembre 4, septiembre 5 .

(1939). Mayo 16, mayo 25, julio 12.

(1940). Febrero 18, febrero 22, abril 25, julio 2.

El Tiempo

(1910). Febrero 7.

La Voz de México

(1892). Abril 9.

(1895). Noviembre 15.

(1896). Noviembre 13.

(1897). Febrero 10.

(1907). Abril 12. 
Periódico Oficial de la Federación

(1937). Mayo 21.

(1940). Noviembre 27.

(2011). Marzo 25.

(2014). Agosto 5.

Periódico Oficial de Estado de Chihuahua (1933). Julio 8.

Periódico Oficial de Estado de Morelos (1933). Marzo 19.

Periódico Oficial del Estado de Aguascalientes (1931). Mayo 10.

Periódico Oficial del Estado de Baja California (1928). Octubre 24.

Periódico Oficial del Estado de Coahuila (1944), mayo 24, septiembre 6.

Periódico Oficial del Estado de Guerrero (1934). Abril 4.

Periódico oficial del Estado de Hidalgo

(1930). Noviembre 24

(1931). Abril 24.

Periódico Oficial del Estado de Michoacán (1931). Junio 1.

Periódico oficial del Estado de Morelos

(1931). Enero 18, abril 19, diciembre 20, junio 17.

(1932). Marzo 13, abril 17, julio 17, octubre 14.

Periódico Oficial del Estado de Puebla (1940). Junio 16.

Periódico oficial del estado de Querétaro (1934). Enero 18.

Periódico Oficial del Estado de San Luis Potosí (1919). Mayo 14.

Periódico Oficial del Estado de Tamaulipas (1930). Diciembre 24.

Periódico oficial del Estado de Tamaulipas (1931). Abril 30.

Periódico Oficial del Estado de Yucatán (1929). Julio 12.

Semana Mercantil (1913). Marzo 10.

Universidad (1931). Enero 1. 